\begin{abstract}
As a science fiction game, Deus Ex: Mankind Divided offers what Csicsery-Ronay Jr. describes as "an image of science" and in this case, it's an image of science that has particular implications for disability (111, emphasis in the original). In this paper the overlaps between disability studies and digital game studies are explored. Mitchell and Snyder's work on disability and narrative prosthesis in literature is applied to Deus Ex: Mankind Divided. Questions about community affiliation, models of disability and individualization are raised. The power implied by erasure-by-metaphor is considered, as are issues of migration, appropriation, disability and the grotesque. It is concluded that applying Mitchell and Snyder's work on narrative prosthesis is productive. By focusing on ability, disability and tangibility, in relation to the game's rules, game-play and the game's narrative elements, this analysis demonstrates the relevance of games to disability studies, and the significance of disability theory to science fiction games.
\end{abstract}

\title{
Bodies That Count: Augmentation, Community and Disability in a Science Fiction Game
}

\author{
Diane Carr \\ UCL IOE University of London
}

Playing Deus Ex: Mankind Divided involves propelling an augmented counter-terrorist agent through a dystopian city warped by intrigue and corruption. Players tweak the protagonist's body, select fantastical augmentations that support strategic ends, and perform these strategies in a fictional world where results are assessed and capacities are quantified. In Screening Space, Vivian Sobchack notes that science fiction has "always taken as its distinctive generic task the cognitive mapping and poetic figuration of social relations as they are constituted and changed by new technological modes" (225). Deus Ex: Mankind Divided depicts radical developments in human augmentation, and links these technologies with turmoil, disability and social collapse.

The significance of disability to Deus Ex: Mankind Divided (aka Mankind Divided) is explored using an adaptation of Mitchell and Snyder's well-known work on narrative prosthesis in literature, and game analysis generated through play. For Mitchell and Snyder, the disruptive potential of the disabled body is the source of its power within narrative. While literature harnesses the potency of stigmatized bodies, this "reliance upon disability in narrative rarely develops into a means of identifying people with disability as a disenfranchised cultural constituency" (55). In Mankind Divided, the disruptive potential of the protagonist's non-standard body is processed through forms of assessment. Yet, if the meaning of Adam Jenson's body is organized by the game's rules and scores, it's also destabilized by play (repetition, alteration), and further disorganized by a narrative that incorporates frequent references to amnesia, violation, secrets and conspiracy. This paper begins with an introduction to Mankind Divided, follows this with a review of relevant methodological and theoretical issues, and then moves into an analysis of the game. [1]

\section{Introducing Deus Ex: Mankind Divided}


With shades of Verhoeven's 1987 film RoboCop, the Deus Ex series incorporates what Joyce (in Cyberpunk and Visual Culture) calls the "staple tropes of cyberpunk" including social fragmentation, rebel hackers, corruption, conspiracy and, crucially, the "fusion of bodies and machines" (156). Joyce argues that digital games have taken "center stage in recent articulations of cyberpunk" and the Deus Ex series is "the medium's preeminent example of cyberpunk" (156). The series launched in 2000. It's set in a future where physical and cognitive augmentations have become increasingly common, and access to augmentation technology has exacerbated existing inequalities. Previous games in the series have focused on tensions between augmented and non-augmented citizens, while exploring aspects of transhumanism (the "fantasy of escape from the finite materiality of the enfleshed self" - Bradotti 91). As Joyce has pointed out, references to transhumanism are common in cyberpunk. In Mankind Divided, the most committed transhumanist is Allison Stanek, a bomb maker and cult leader who urges her acolytes to "free yourself from the prison of the flesh" by plugging into a machine that kills them. Transhumanism is not depicted as a particularly viable choice in Mankind Divided and its downgrading is one indication that the meaning and value of augmentations has undergone a change.

Deus Ex: Mankind Divided (2016) has close ties to its prequel, Deus Ex: Human Revolution (2011). The conclusion of Human Revolution saw millions of the world's augmented people remotely hacked in a disaster that became known as 'the aug incident'during which "mechanically augmented citizens all over the world were stripped of control over their minds and bodies, resulting in the deaths of millions". The game links augmentations with disability, and disability with social collapse. [2]

As a game played on a console Deus Ex: Mankind Divided involves various forms and degrees of human/machine fusion. The protagonist, Adam Jensen, is controlled by the player. Adam's potential actions are drawn from a limited repertoire (e.g. walk, hide, carry, climb, throw, shoot, etc.). These actions connect the player to Adam through the commands, and connect Adam's body to the spaces he occupies. If, for instance, the player presses the square button on the PlayStation4 controller to open a door it will work, so long as Adam is standing in front of a door that can be opened. Adam might perform various accidental actions during play - falling down a lift shaft, getting lost, or hiding in full view of heavily armed assailants. Different versions of Adam will be actualized. 'My' Adam is polite, reckless and impatient. Another player might perform an Adam who is stealthy and risk averse. There is scope for accidents and customization, but the player will encounter the same major characters, core missions and locations

Mankind Divided offers players four main strategies: stealth (sneaking, hiding, exploring), confrontation (armed and unarmed combat), social (perceptive and persuasive), and hacking (bypassing locks, passwords and codes). Each strategy is directed at the overcoming of obstacles. Obstacles take the form of guards, police, barriers, henchmen and security systems. Adam explores a dystopian version of Prague, encountering armed drones, bombings and brutal policing. He witnesses the forced segregation of the traumatized and reviled augmented survivors. Playing the game involves moving through a series of missions. Some are required in order to progress, others are optional. Missions generally involve travelling to a particular location in order to complete a specific action (e.g. collecting evidence from a crime scene, or locating a suspect). Failures might involve frustration, repetition, or Adam's temporary death. There is no significant penalty for getting Adam killed. Success involves 'pick ups' (painkillers, energy boosters, ammunition), the awarding of points, and onward progression. 
Mankind Divided is a role-playing game in the broad sense that players will "play the role' of Adam Jensen, and in the sense that it incorporates a number of Role-Playing-Game (RPG) rules and conventions. In a generic RPG, success during play leads to the accumulation of 'experience points' (XP) that can be used to incrementally development a character's specialist skills; to increase a character's resilience or agility, for instance. In Mankind Divided, the points acquired during play are spent on the development of Adam's augmentations. When players open Adam's augmentation menu they are presented with a set of options. They might prefer to invest points in Adam's cognitive augmentations (for hacking or perceptual skills), or chose to improve his aim, energy levels, or speed.

\section{Method and theory}

In recent years a growing number of game studies publications have emerged that reference critical disability studies literature (e.g. Ledder; Champlin; Gibbons "Playing"; Carr "Ability") including Mitchell and Snyder's work (Carr "Bodies"; Gibbons "Disability"). Humanities research at the overlap between game studies and disability studies has the potential to problematize the dominance of clinical perspectives in the field, and help make visible the extent to which "ideologies of ability" (Siebers 7) depend on the abjectification of disability.

Analysis generated through play is a common approach in game studies, particularly for those interested in representation and cultural politics. It generally involves the "exploratory application of a specific theory [of something] to a game, through play" (Carr Methodology) although what this means in practice might vary wildly depending on the genre of game, the manner in which play is (implicitly or otherwise) conceptualized, and the aims of the analyst. One of the first issues a game analyst will face is that of scale. According to various player wikis, playing Mankind Divided 'straight through' takes approximately 20 hours, or up to 40 hours if players complete the optional side-missions. The game rewards meandering and snooping. In addition to exploring the city, climbing into stranger's apartments, checking their cupboards, or reading their newspapers and emails, players have the option of having Adam engage in short, scripted conversations with bystanders, colleagues and bartenders. What's more, the game's 'edges' blur into prequels and spin-offs, comic books, player guides, reviews and promotional materials. As well as being extensive, the game is variable. Players (including player analysts) will perform relatively different versions of Adam depending on their strategic preferences, the dialogue options they select and the routes they take. [3]

I have played the game till completion, yet there are side-missions that I missed, minor characters that I've not spoken with, dialogue options I've not exhausted, strategies I've not tried, and laptops that I didn't hack. In recognition of the game's variability and scale, this approach to analysis involves fragmentation, acknowledged omission, and the production of a situated, embodied interpretation - with all the contingency that implies. Each fragment of the game is a composite. If Adam pauses in a puppet store in Prague, that moment consists of Adam in his setting (a man in a shop), the resources that he is carrying (his inventory screen), a list of the things that he is supposed to be doing (his mission updates), copies of the written material that he has collected, and the screen that breaks Adam's body into a set of current and potential augmentations. Then there are the loading screens that 'book end' play, and the cut-scenes (animated sequences) that link levels of the game together while contributing to the game's narrative and contextualizing the missions to 
come. Games do not comply with conventional narrative models (Frasca) and yet this emphasis on instances and moving between strata is reminiscent of Barthes' comments on narrative structure:

narrative is a hierarchy of instances. To understand a narrative is not merely to follow the unfolding of the story, it is also to recognize its construction in 'storeys', to project the horizontal concatenations of the narrative 'thread' on to an implicitly vertical axis (87).

This analysis of Mankind Divided involved playing the game and then revisiting fragments collected as screenshots, reflecting on how these elements connect to the wider game, and considering these fragments and connections through concepts adapted from Mitchell and Snyder's account of 'Narrative Prosthesis and the Materiality of Metaphor'.

Game researchers have found the notion of metaphor suggestive because games incorporate a series of substitutions: one action for another, one space for another, one body for another. Juul argues, for instance, that the "player's real-world actions have a metaphorical relation to the fictional in-game action" because pressing the right button results in an effective action within the game by the protagonist (Juul 196). A review of different approaches to metaphor found in disability studies literature, and an account of how each might be applied to games is not attempted here [4]. Nor do I review the various ways that specific theories of metaphor might adapt to play, games or simulations (see Möring). For the sake of this analysis, what's needed is a definition of metaphor that is derived from Mitchell and Snyder's work, and that can be applied to representations of disability in this game. In this paper, then, the term 'metaphor' is used to refer to instances where the game's themes are made tangible (47-8). Mitchell and Snyder begin their account with a consideration of disability as 'problem': disability is a form of deviance that calls forth cultural and institutional efforts at containment, control or compensation (47). This preoccupation with the management of impaired bodies is expressed in literature in two ways. Firstly, it appears on bodies as evidence of distinctiveness. Secondly, disability is present in narrative as "a metaphorical signifier of social and individual collapse" (47). These "two principle representational strategies" (48) mean that disability is present within narrative, giving material form or lending tangibility to themes of social upheaval, for instance.

Yet, as the authors note, these same narratives rarely concern themselves with the complexities of disability-as-lived. In The Steadfast Tin Soldier, for example, the toy's missing leg is mentioned at the beginning of the tale, differentiating the soldier from his more standard comrades, but it's not mentioned during his adventures: "the deficiency inaugurates the need for a story but is quickly forgotten once the need is established" (56). The flaw triggers the narrative, and the narrative seeks to resolve this supposed deviance by either ignoring it, or punishing it (56). Mitchell and Snyder explain that they are interested in "texts that not only deploy but explicitly foreground the "play" of multiple meanings as a facet of their discursive production" (p. 48), where this proliferation of meaning is linked with unstable and deviant bodies. The notion of an unstable body generating multiple meanings is relevant to games like Mankind Divided, because games are literally played, and because the development of the central character is one of the things that players play with.

For Mitchell and Snyder, the unmarked body "enjoys its cultural anonymity" (57) whereas disability "signifies a more variegated and sordid series of assumptions and experiences" and inevitably attracts attempts to tame, smooth, control or contain its 
"unruliness" (57) The authors point out that lived experience of disability potentially impacts on subjectivity, yet within narratives the idea of a correspondence between an inner and exterior life is simplified: Either the "deviant" body deforms subjectivity, or "deviant" subjectivity violently erupts upon the surface" of the body (57). This idea of a direct correspondence between internal and external 'deviance' combines physiognomy with the symbolic. As a result, disability is culturally constructed as 'decipherable'. Mitchell and Snyder argue that "disability inaugurates an explanatory need that the unmarked body eludes by virtue of its physical anonymity" (60) and this explanatory need is evident in ongoing attempts to explain, resolve, contain, fix, cure or eradicate the disabled body. These points have particular implications for a science fiction game, given the genre's preoccupation with technology as cure (Allan), the repeatability of play (the sense that, through repetition, something troubling is being worked on or worked out), and the yearning for decipherability suggested by the testing, assessment and quantification of the body during play. In addition to highlighting a role in "giving body to belief" (63) in narrative, Mitchell and Snyder link disability with forms of strategically useful insight, pointing out, for example, that Oedipus proves himself to be uniquely equipped to answer the sphinx's riddle: "Whereas disability usually provides the riddle in need of a narrative solution, in this instance the experience of disability momentarily serves as the source of Oedipus's interpretive mastery" (61). Based on Mitchell and Snyder's account of narrative prosthesis, this analysis of disability in Mankind Divided will focus on materialization, theme and tangibility, representations of knowledge, disavowal and erasure.

\section{Analyzing Deus Ex: Mankind Divided}

Adam Jensen climbs a ladder after an eventful afternoon in sunny Prague and begins the journey back to his apartment. His recent adventures have emphasized the extent to which augmentations are now associated with 'the underground'. He has just visited a hacker clinician in a basement; a grungy, hidden lair that featured dangling sets of prosthetic arms and legs. Already heavily augmented, he has discovered that he was fitted out with an additional set at some point in the past two years. He does not know who fit the augmentations, or why.

As with other games in the Deus Ex series, Mankind Divided features themes of social crisis, corruption and violation. The new augmentations hidden in Adam Jensen's body are only revealed when injury rendered his existing augmentations unstable. These mysterious and unreliable augmentations were fitted while he was missing and presumed dead. There are questions about what Adam knows, how he knows it, and frequent references to unreliability, perspective, causality, and evidence. Adam is an amnesiac double agent, and it is not always clear (to Adam or the player) who he is working with, or for. He encounters duplicitous spies, conspiracies, hackers and bugs. Knowledge is unreliable and chimeric in the game's narrative, while in the game-as-played, knowledge is implicated in the identification of effective strategies and their implementation, with success rewarded by progression, goal attainment and experience points.

Players access Adam's body-as-anatomy to invest awarded points in physical and cognitive augmentations. As this suggests, some aspects of his body are rendered tangible when quantified: the experience points he needs to 'level up' an augmentation, the amount of energy used, damage done or healing required. It might seem as if descriptive accounts of Adam's body would be a feature of the game's narrative aspects, while quantification might be the remit of the game's rules, but any such allocation collapses under the weight of detail 
that is provided. Consider, for example, ammunition described as "liquid crystal elastomer projectiles, molded into a frangible diffusion matrix and spin-stabilized for maximum range", or this description of an augmentation that allows Adam (and hence the player) to track targets: "Advanced functionality is provided by an onboard LIDAR laser scanner and electromagnetic field interpreter". An augmentation for Jensen's eye (The Eye-Know Retinal Prosthesis) apparently "provides data on the user's medical condition, available equipment, wireless access to personal data storage, and direct audio/visual telecommunications". These descriptions emphasize the game's interest in knowledge (with references to scanning, tracking, tagging and interpretation) at the same time as recalling Csicsery-Ronay Jr.'s suggestion that "Every quantum-info-nano-bio-cyber-astro-psycho-xeno-socio-physical infodump pumps up the illusion that sf stories are dramatizations of scientific knowledge" (111).

Adam's augmentations materialize his difference. Yet the connections between these 'infodumps', the themes of the game, and the strategies afforded by his augmentations indicate a parallel interest in the materializing of ability. This claim is complicated, because Adam's new augmentations are unstable. This instability is marked by 'glitches' on his augmentation screen and in reminders of their inexplicable origins. The instability of his augmentation technology brings the 'positive' of ability into close contact with the 'negative' of disability. The augmentations are conduits. Enabling on the one hand, disabling on the other. In this way, the augmentations give material form to what has been described as one of the most threatening aspects of disability from a normate perspective: disability can be acquired (Thomson 14). Just as in the 'aug incident' - when millions of professional, privileged people found themselves suddenly classified as disabled.

Deus Ex: Mankind Divided makes frequent references to this aug incident which took place during the climax of the game's prequel Deus Ex: Human Revolution. The aug incident was triggered by Hugh Darrow, a non-augmented disabled character who combines Mitchell and Snyder's references to physiognomy (i.e. disability as the materialization of internal deviance, 59-59) with the ambitions of a generic 'mad' doctor (see Smith) and the resources of a Bond villain. With the flick of a switch, Darrow hacked augmented people around the world, sending them into a spectacular, collective meltdown. The connecting of disability with social collapse is explicit. To quote from a loading screen: "Welcome to the Divided World [...] two years after a madman's attempt to teach the world a lesson sent millions of mechanically-enhanced people into a killing frenzy [...] against this backdrop of chaos, one man will struggle to expose its true source". Darrow's disability is used to explain his villainy, which propels him into further disability (his 'madness') which drives an outbreak of mass disability, which cascades into an apocalypse. As is typical in this conspiracy-riven cyberpunk world, Darrow is described as directly responsible and yet not responsible (not the "true source"), and this gap is another reminder of Adam's problems with unreliable knowledge.

As a result of Darrow's hack, society has been militarized and augmented people are now shunned by the 'naturals' (non-augmented humans). In divided cities, antagonists including the police use 'you' to collectively refer to augmented humans. The 'naturals' that Adam encounters might not technically be able-bodied, yet they occupy the position of the able-bodied in that they constitute a dominant 'them' relative to the marginalized 'us' ('augs', 'cranks', 'hanza' or 'cogs') of the augmented population - which includes Adam. As this suggests, the game's dialogue uses pronouns ('we' 'us' 'your people') to map out an ephemeral geography of provisional community. These pronouns sketch out a solidarity 
based on marginalization, as when activists, rebels and hackers of various genders, ethnicities and nationalities refer to 'we' and 'us' when speaking to the militaristic, (apparently) white, male North American counter-terrorist agent Adam Jensen. For example, activist Alex Vega reminisces with Adam: "I really hate this city. It used to welcome people like us", and the disappointed bomb-maker Allison Stanek tells Adam: "I believed you were one of us" to which he responds: "I am. I just have a more inclusive idea of who us is." [5]

Adam is fitted with powerful augmentations that enable him to perform 'super human' feats. That might be considered a basis for arguing that his augmentations empower him beyond some kind of species-wide baseline, and hence that he is not disabled. But that would necessitate overlooking the relationships between power, the natural and neutrality as set up by the game. Adam's augmentations mark him as powerful in an immediate, literal sense (i.e. he can punch through walls) but as disempowered in a persistent, social sense. He experiences marginality on the basis of his augmentations, and discovers community on the basis of marginality.

This doesn't mean that his affiliations are straightforward. He is a double agent, infiltrating TF29 (Interpol's new counter-terrorist unit) on behalf of the Juggernaut Collective (hackers and activists), while it might be that the strings at TF29 are being pulled by the illuminati - and it is not clear if the Juggernaut Collective recruited Jensen to infiltrate TF 29, or if the illuminati orchestrated his recruitment by the Collective. His problems with information continue while his augmentations continue to 'out' him to other characters. To return to Mitchell and Snyder, Adam is exceptional by virtue of disability. Yet his differences don't disappear once the game begins. Disability is not rendered undetectable by its role as a metaphor for 'something else'.

This is significant given the frequency with which disability is used and then erased in narrative. Mitchell and Snyder cite Longmore's work to argue that: "we are trained to compartmentalize impairment as an isolated and individual condition of existence. Consequently, we rarely connect together stories of people with disabilities as evidence of a wider systemic predicament" (51). Representations of disability tend to "reflect the medicalized view that restricts disability to a static impairment entombed within an individual" (19). The presence of narrative prosthesis rarely converts into recognition of people with disabilities as a "disenfranchised cultural constituency" (55) because characters are marked as exceptional through disability, and being exceptional means ruling out "shared social identity" (55). In addition to being molded into a particular pattern through ubiquitous individualization, disability is obscured by its own metaphoric potentials. As Allan has argued in her work on science fiction, disability and technology: "the disabled body stood in for a whole host of socially constructed and marginalized otherness" (7). As Smith points out in her analysis of eugenics discourse and the interpretative conventions associated with classic horror: "a genre identified by its representations of aberrant bodies [...] has rarely considered the disabled individual as one of the Others connoted by the monstrous body" (2627). Screen media has repeatedly used disabled bodies as placeholders for difference and deviance (Mogk p 2-3).

The tendency to erase disability by isolating it, individualizing it, and then interpreting it as a stand-in for some alternative form of otherness does not apply to Deus Ex: Mankind Divided. Disability acts as civilization's death knell without becoming obscured or disavowed. The first reason for this is that the game represents disability as socially and 
environmentally constructed. As Gibbons (Playing) has pointed out in her analysis of the game's prequel, by connecting new technologies with changing perceptions of ability, disability is shown to be created in context and "shaped by environments". Secondly (and this is a related point), disability escapes erasure because Adam Jenson is the member of a community. He discovers that "shared experience of stigmatization creates communality" (Thomson 15). Thirdly, disability doesn't disappear because the game doesn't use disability to indicate Adam's exceptionality and then disregard how disability might impact on his life - he has to manage dodgy augmentations, keep an eye on his energy levels, and queue at checkpoints. He gets called names.

If disability manages to avoid disappearance-by-metaphor in Mankind Divided in part because it is depicted as a basis for community, then the game's representation of disability needs to be considered alongside its references to workers and migration. The game's loading screens feature brief histories of Dubai and Prague that link the scale and devastation of the aug incident with an economic boom during which, in the case of Dubai: "the city welcomed thousands of augmented workers into its midst". It does not appear to be the case that migration is used as a metaphor for disability, or that disability is used as a metaphor for migrant experience. Aspects of one are not appropriated to express aspects of the other. It is more that the two are co-joined, and augmentation is the link. The workers invested in augmentations to secure employment. They relocated to take up employment. The workers and then their cities broke down when the technologies failed. Adam himself is a migrant worker, but he is also an intense mix of privilege and authoritative masculinity housed in an extensively and repeatedly violated body. His body keeps getting taken away and altered without his consent. It has happened to Adam twice in the game's backstory, and it happens again each time the player opens up the game's augmentation screen and starts tinkering. What the game does, by linking mobility and disability together, is emphasize that it is mutability itself (the idea of changing identities, or potential changes to status) that is threatening. Augmentations materialize this volatility and uncertainty. The game depicts social marginalization as barbaric - while echoing contemporary 'austerity' discourse in which 'healthy' nations are framed as being at risk of being swamped by undeserving outsiders and drained by deviant insiders. As Mitchell and Snyder have pointed out, the urge to explicate disabled bodies within narrative is a reflection of a wider cultural tendency, while the:

necessity for developing various kinds of cultural accommodations to handle the "problem" of corporeal difference (through charitable organizations, modifications of physical architecture, welfare doles, quarantine, genocide, euthanasia programs, etc.) situates people with disabilities in a profoundly ambivalent relationship to the cultures and the stories they inhabit (47)

Deus Ex: Mankind Divided represents disability as a social construct, depicts communities of disabled people, and describes these communities as oppressed on the basis of their difference. Disability is not subject to conventional individuation and disavowal. It doesn't follow that disavowal is not taking place. Consider, for example, the character of Nathanial Brown.

Nathanial Brown is a wealthy corporate executive, apparently white, male and ablebodied. He's implicated in exploitative labor practices and questionable 'development' projects. In a conversation that takes place at the start of one of the game's final missions, Brown speaks of his struggles against "anti-aug racists" and complains to Adam about 
"trying to save the lives of your people". The Deus Ex version of Prague features forms of segregation (housing, transport, seating, etc.) that are formalized by signage and enforced by violent police. In these ways the game references histories of segregation on the basis of race, but when Brown uses the term "anti-aug racist" he is not so much referencing a history as appropriating it. It's the same kind of disavowal and erasure that Mitchell and Snyder have described, but in this instance, the appropriation is made on behalf of subjects positioned as disabled, by a subject positioned as normate (Thomson 8). In the process, an intersectional space is collapsed, 'disappearing' the subjects within (see Erevelles and Minear, Titchkosky for more on intersectionality, disability and race). Brown's appropriation is a strategy that suggests that he's at a loss when he wants to refer to collective oppression on the basis of disability. It's also a reminder that the game does not link the dystopian segregation depicted by the game, with contemporary segregation created by inaccessible public space. Brown's appropriation is combined with a statement of determination to save "your people". His declaration draws a line, placing Jensen and his community on the Other side. Brown's dialogue is a demonstration of appropriation and disavowal in metaphor, and a performance of the privilege that makes such appropriation possible.

In contrast to Nathanial Brown, the mercenary Victor Marchenko's body is emphatically 'marked'. Victor is a major antagonist in the game (the 'final boss'). He is huge and blond-white, heavily accented and well-read. His body is a bulging combination of scars, flesh and weaponry. It's not particularly clear where he is from or who Victor works for, yet he makes frequent, mocking reference to Adam's misplaced loyalties (as a sell-out; a 'brother' kept 'on a leash'). Adam is abject relative to Brown, while Victor is abject relative to Adam. Victor's body recalls Csicsery-Ronay Jr.'s description of the science-fictional grotesque as "the struggle to accommodate mutable, unstable objects and beings in the world" (182), which is particularly suggestive when considered alongside Mitchell and Snyder's references to tangibility. Building on Bakhtin's work, Csicsery-Ronay Jr. writes about corporeality as a problem for regulatory systems - including science. If the sublime involves the unfathomable, the grotesque "traps the sublime in the body" (182) making it unstable, distorted. Recalling Freud's uncanny, or Kristeva's descriptions of the abject, and suggesting a collision between empiricism and the unfathomable, the grotesque involves "liminal beings that defy classification because they somehow collapse natural boundaries" (187).

There were times during the prequel (Human Revolution) when the felt like a metaphor for 'passing', because Adam spent much of the game entering different workplaces by stealth and trying to avoid detection for as long as possible. In Mankind Divided Adam has the option to partially integrate at least (through his work) while other characters (including Victor) make tangible the limits and conditions of integration. As a grotesque, Victor Marchenko epitomizes all that can't be accommodated by the regulatory systems present within the game's fictional world. As such, Victor is a vivid reminder that playing Mankind Divided involves repeatedly testing the conditional 'fit' between a body (Adam, as the played protagonist) and a regulatory system (the game).

\section{Conclusion}

Through this analysis of Mankind Divided, questions have been raised about the significance of community affiliation when depicted in proximity to disability, the forms of appropriation and erasure that support metaphor, and the place of the 'science fictional grotesque' (Csicsery-Ronay Jr.) in games as regulatory systems. Adapting Mitchell and 
Snyder's literary theory for the analysis of a game entails reflecting on tangibility and metaphor, and the relationship between the game's narrative, rules and goals. It involves thinking about the ambiguous or unstable aspects of the protagonist's body as it emerges through play, alongside the game's construction of ability as quantifiable.

In Mankind Divided, augmentation technology materializes disability's power to radically change the social status of a subject. Because augmentations and social crisis are linked with disability, the game represents a contextualized, constructed, collective version of disability. It links marginalization with community formation. Disability escapes erasure or disavowal because it avoids individualization. Disability is not a stand-in for some other form of otherness in Deus Ex: Mankind Divided. A community of augmented survivors live with oppressive surveillance, drones, queues, border patrols and identity checks. These disciplinary routines echo Mitchell and Snyder's description of the construction of disability as problem, and recall historical as well as contemporary efforts to resolve this 'problem' through institutionalization, medicalization and eugenics. Applying concepts from Mitchell and Snyder's work to Deus Ex: Mankind Divided has helped to show how erasure works in metaphor, and the forms of privilege and appropriation on which such metaphors depend. Popular culture, including science fiction games, help to make these patterns visible. Thanks to its anxious focus on the relationships between bodies and classification, technology, stigma and social status, Deus Ex: Mankind Divided offers a vocabulary to researchers with an interest in the critique of able-identified, mainstream culture.

Notes

1. In Mankind Divided, a non-standard body is at the centre of a series of assessments. In many other games, an ostensibly normate body is subjected to peril, threatened by disability, and evaluated (Carr, Vulnerability and Validation; Ability)

2. These quotes are from the publisher's website, online at https://www.deusex.com/ Screenshots, links to cut scenes, and examples of dialogue from Deus Ex: Mankind Divided are at https://playhouse.wordpress.com/category/games-ability-anddisability/.

3. One of the risks associated with game analysis, thanks to issues of scale, variability and emergent paratexts is the likelihood of missing a detail (e.g. a dialogue option, a character, or a marketing ploy) that is relevant, disturbing or repellent until after the analysis is complete and reviewed. This is relevant to Mankind Divided and aspects of its reception and marketing. I hope to address this in a follow-up paper. While on the topic of aggravation - it is noted that the universalizing term 'mankind' is annoying. 
4. For more on metaphor and disability, see Vidali, Sobchack or Titchkosky. For more on representation, community and disability see Smith (113) and Hawkins. For an application of narrative prosthesis to film genre, see Snyder and Mitchell (Body), and for an application to science fiction television, see Patsavas.

5. Adam Jensen is white looking/white passing, but he was adopted and his birth parents are not been identified. If you're curious about Adam's background, or about the depth of detail provided in these games, try this walkthrough at YouTube (from the previous game in the franchise) at around 1:08 https://www.youtube.com/watch?v=oXjSQ4c_GuA

\section{Acknowledgements:}

This work was undertaken as part of an AHRC funded large consortia project titled 'Disability and Community: Dis/engagement, Dis/enfranchisement, Dis/parity and Dissent' (AKA the D4D Project). The author thanks the reviewers and editors for their time, patience and insight. Parts of this analysis were shared as a work-in-progress at DiGRA 2018. See the DiGRA online library for abstracts, or visit https://playhouse.wordpress.com/

\section{References}

Allan, Kathryn. (2013.) "Introduction: Reading Disability in Science Fiction". In K. Allan (Ed.), Disability in Science Fiction: Representations of Technology as Cure New York: Palgrave Macmillan. 2013 1-18. Print

Barthes, Roland "Structural Analysis of Narratives" in Image, Music, Text. Fontana Press. 1977. Print.

Champlin, Alexander. "Playing with Feelings: Porn, Emotion, and Disability in Katawa Shoujo". Well Played. Vol 3 No 2. 2015. Web.

Carr, Diane "Methodology, Representation, and Games". Games and Culture Online first version, 2017 http://journals.sagepub.com/toc/gaca/0/0 Web.

Carr, Diane "Delicate Subjects: Vulnerability and Validation in Action Adventure Games" paper for the Digital Games Research Association annual conference, 2016, Dundee. https://playhouse.files.wordpress.com/2016/06/final-digra-carr-delicate-subjects.pdf

Carr, Diane "Bodies, Augmentation and Disability in Dead Space and Deus Ex: Human Revolution'. In Context Matters! Exploring and Reframing Games in Context. Proceedings, FROG 2013, Vienna September 27-28th 2013. K. Mitgutsch, S. Huber, J.Wimmer, M. G. Wagner, H. Rosenstingl (Eds.) Vienna. New Academic Press Org. 2013, 31-41. Print.

Carr, Diane “Ability, Disability and Dead Space”. Game Studies. Vol 14 Issue 2 December 2014 Web. 
Carr, Diane "Constructing Disability in Online Worlds; Conceptualising Disability in Online Research". London Review of Education: March 2010, 8: 1, 51-61. Web.

Csicsery-Ronay Jr, Istvan. The Seven Beauties of Science Fiction. Middletown: Wesleyan University Press, 2008. Print.

Erevelles, Nirmala, and Andrea Minear. "Unspeakable offenses: Untangling race and disability in discourses of intersectionality." Journal of Literary \& Cultural Disability Studies 4, no. 2. 2010: 127-145. Web.

Frasca, Gonzalo. "Ludologists love stories, too: notes from a debate that never took place" in DiGRA '03 - Proceedings of the 2003 DiGRA International Conference 2003. Web.

Gibbons, Sarah 'Playing for Transcendence: Deus Ex: Human Revolution and Disability'. In First Person Scholar, October 2013. Web

Gibbons, Sarah "Disability, Neurological Diversity, and Inclusive Play: An Examination of the Social and Political Aspects of the Relationship between Disability and Games" in Loading... Vol 9 (14): 25-39. 2015 Web.

Hawkins, Joan. "One of Us": Tod Browning's Freaks. In Freakery, R.G. Thomson (Ed) New York: New York UP. 1996. 265-276. Print

Joyce, Stephen. "Playing for Virtually Real: Cyberpunk Aesthetics and Ethics in Deus Ex: Human Revolution." In Graham J Murphy and Lars Schmeink (eds.) Cyberpunk and Visual Culture. 2017. 155-173. New York: Routledge. Print.

Juul, Jesper. Half-real: Video Games Between Real Rules and Fictional Worlds. MIT press, 2011. Print.

Ledder, Simon "Evolve today!": Human Enhancement Technologies in the BioShock universe. In L. Cuddy (ed.) BioShock and Philosophy, Oxford: Wiley-Blackwell. 2015. Print

Mitchell, David T. and Sharon L. Snyder Narrative Prosthesis: Disability and the Dependencies of Discourse. Ann Arbor: U of Michigan P. 2000. Print

Mogk, Marja Evelyn 'Introduction: An Invitation to Disability' in Different Bodies: Essays on Disability in Film and Television. M.E. Mogk (ed.) Jefferson NC: McFarland and Company Inc. 2013. Print.

Möring, Sebastian "Tackling the Metaphor-Simulation Dilemma" in Proceedings of DiGRA Nordic 2012 Conference: Local and Global - Games in Culture and Society. (2012) Web. 3 November 2017.

Patsavas, Alyson. "Extra-Textual Reveals: Disability, (Sort of) Queer Sexality and a Military Coup in Battlestar Galactica". In Different Bodies, M.E. Mogk (Ed.) Jefferson: McFarlane and Company 2013. 131-144. Print

Rosi, Braidotti. The Posthuman. Cambridge: Polity 2013. Print. 
Siebers, Tobin. Disability Theory. Ann Arbor: U of Michigan P. 2009. Print.

Smith, Angela. Hideous Progeny: Disability, Eugenics, and Classic Horror Cinema. New York: Columbia UP, 2011. Print

Sobchack, Vivian C. Screening Space: The American Science Fiction Film. New York: Ungar. 1993. Print.

Snyder, Sharon L. and David T. Mitchell Cultural Locations of Disability. Chicago: U Chicago P 2006. Print.

Snyder, Sharon L. and David T. Mitchell. "Body Genres: An Anatomy of Disability in Film" in The Problem Body, S.Chivers and N.Markotic (Eds.) Ohio State UP. 2010. 179-206. Print.

Titchkosky, Tanya. "Life with dead metaphors: Impairment rhetoric in social justice praxis." Journal of Literary \& Cultural Disability Studies 9, no. 1 2015. 1-18. Web.

Thomson, Rosemarie Garland. Extraordinary Bodies: Figuring Physical Disability in American Culture and Literature. New York: Columbia UP. 1997. Print.

Vidali, Amy. "Seeing What We Know: Disability and Theories of Metaphor." Journal of Literary \& Cultural Disability Studies, vol. 4 no. 1, 2010, 33-54 Web.

\section{Games referenced:}

Deus Ex: Mankind Divided released 2016 (dev Eidos Montreal, publ. Square Enix), PS4 version.

Deus Ex: Human Revolution, released 2011 (Dev. Eidos Montreal, Publ. Square Enix), PS3 version. 